\title{
The Explainable Business Process (XBP) - An Exploratory Research
}

\author{
O Processo de Negócio Explicável (XBP) - Uma Pesquisa Exploratória
}

\author{
Riham Alhomsi ${ }^{1 *}$, Adriana S. Vivacqua ${ }^{1}$
}

\begin{abstract}
Providing explanations to a business process, its decisions and its activities, is an important factor to achieve the objectives of the business process, and to minimize and deal with any ambiguity in the process that may cause multiple interpretations, as well as to engender the appropriate trust of the users in the process. As a first step towards adding explanations to business process, we present an exploratory study to merge the concept of explainability and business processes, and we propose a conceptual framework to use explainability with business process in a model that we called the Explainable Business Process (XBP). Furthermore, we propose an XBP lifecycle, based on the Model-based and Incremental Knowledge Engineering (MIKE) approach, in order to show in details the phase where explainability fits in the business process lifecycle, noting that we focus on explaining the decisions and activities of the process in its as-is model, without transforming it into a to-be model.
\end{abstract}

Keywords: Business Process - Explainability — Explainable Business Process

Resumo: Fornecer explicações para um processo de negócios, suas decisões e suas atividades, é um fator chave para o processo alcançar os seus objetivos, e para reduzir e lidar com quaiquer ambiguidades no processo, que venham a causar múltiplas interpretações, bem como para gerar a confiança dos usuários no processo. Como um primeiro passo para adicionar explicações ao processo de negócios, apresentamos um estudo exploratório, para trazer o conceito de explicabilidade ao processo de negócios, e propomos uma estrutura conceitual para usar a explicabilidade com processo de negócios em um modelo que chamamos de Processo de Negócios Explicável (XBP), além disso, propomos o ciclo de vida do XBP baseado na abordagem Baseada em Modelo e Engenharia do Conhecimento Incremental (MIKE), a fim de mostrar em que fase do ciclo de vida do processo de negócios a explicabilidade se encaixa, observando que nos concentramos em explicar as decisões e atividades do processo em seu estado atual (as-is) sem transformá-lo em um futuro modelo (to-be).

Palavras-Chave: Processo de Negócios - Explicabilidade - Processo de Negócios Explicável

${ }_{1}^{1}$ Programa de Pós-graduação em Informática, Universidade Federal do Rio de Janeiro, Rio de Janeiro, Brazil

*Corresponding author: rayhomsi7@gmail.com

DOI: http://dx.doi.org/10.22456/2175-2745.107964 • Received: 30/09/2020 • Accepted: 07/12/2020

CC BY-NC-ND 4.0 - This work is licensed under a Creative Commons Attribution-NonCommercial-NoDerivatives 4.0 International License.

\section{Introduction}

Business processes can be defined as a collection of activities that take one or more kinds of input and creates an output that is of value to the end-user [1], or a specific ordering of activities across time and space, with a beginning and an end, and clearly defined inputs and outputs [2].

Traditional modeling techniques, such as structured analysis, data-flow diagrams and entity relationship diagrams describe what a business process is, but they cannot explain the reason behind its motivations, intents, activities, decisions and rules [3].

Guidotti et al. [4] state that the explanation of business processes is necessary for a company to create a trustable and safe business process. The problem of not having explanations is that the decisions are based on a blackbox model. A blackbox business process is a model whose internal decisions and actions are ambiguous for the users. When the reasoning behind the business process is unclear, users are less likely to trust that business process, and that might lead not only to user frustration but also to future complications in the organization.

The main objective of this research is to explore the possibility of having a business process that is explained in the sense that the process' users understand exactly why the decisions, the activities and the actions in this business process are made, taken or requested, so they really understand the 
reason behind the business process as a whole and in details, this would make the business process more understandable, clear, easy to execute and trustful.

This paper is concerned with answering the following questions:

- Is it possible to bring in the explainability concept to be applied to Business Processes?

- How could this application be done?

- What could be the result of applying explainability to a business process?

- What could be the benefits of this application?

This research presents an exploratory study of bringing in the concept and techniques of the explainability (that have been applied in AI) to the Business Process world, in attempt to provide a new concept i.e. the explainable business process that aims to add an explanation layer to an as-is business process model by providing the rationale behind its activities and decisions which makes the business process more understandable, transparent and explained.

Although there are several research studies that discuss parts of the two concepts, a thorough search of the relevant literature did not yield any article related to this exact topic; thus, this research may open the door to future research efforts in this context.

Many organizations realize the importance of making their business processes more transparent, easily understandable and interactive to the users. One way to do that is to provide answers and supporting information to every detail and to a huge number of users many times, which is not always applicable or affordable.

They still need to provide extra information to the users to let them know what are the reasons behind some decisions and get answers to questions of why does the business process do something and not something else, when do some activities succeed and when they fail, how can the user interact effectively to get the desired outcome and why certain actions and information needed to be provided while others are not, in order to provide an overall comprehension and trust in the business process that would lead to increase efficiency, results success and response rates with the process along with user satisfaction, cost reduction and revenue increase.

This research might be also relevant to organizations with need to make their business processes explained when actually re-analyzing the process, re-designing and testing are not an option for them, for example the governmental processes or very complicated processes that cross multiple organizations.

Adding explanations to a business process might increase the complexity of the suggested model especially in the explanations building and the explanations evaluation steps, for the explanations have to be relevant, appropriate and useful. Also, at the end of the first cycle of adding explanations, the human experts have to evaluate the explanations based on the end-user feedback and the actual success rate in order to measure process performance and user trust and satisfaction.
This also increases the level of complexity to the model and to the business process. Human experts' efforts in building explanations model and the continuous improving of the explanations are extra costs of the model, while from the user side the model does not increase any complexity or cost, on the contrary, it aims to reduce complexity and cost.

The rest of this paper is organized as follows. Section 2 presents the method followed to investigate the purpose of the research and to conduct the research. Section 3 presents the literature review of the Business Process Management, Business Process and Business Process Lifecycle, also it presents the definition of explainability concept and presents related work that discussed Business Process with explainability. Section 4 presents the MIKE ${ }^{1}$ approach. Section 5 presents the reference study of applying explainability in Artificial Intelligence which is known as the Explainable AI (XAI). Section 6 presents the suggested conceptual framework of the Explainable Business process (XBP), the suggested XBP lifecycle and the XBP metrics based on the previous study of XAI. Section 7 presents the discussion and the answers to the research questions. Section 8 presents future work and finally, Section 9 presents the conclusion.

\section{Method}

The main method that structures this research included studying the Business Process Management, Business Process and Business Process Lifecycle in related references, then investigate the explainability concept regarding its definition and related literature review and previous studies, after that, we analyze the approach of explainability with business process mentioning the related work of these two concepts.

We also present Explainable Artificial Intelligence (XAI) as a reference of the application of the explainability concept in artificial intelligence, its concept, framework, process and metrics.

Based on this application, we propose a conceptual framework of the Explainable Business Process (XBP) that aims to add an explanations layer to the business process where an alignment between explainability and business processes is discussed and then we suggest the XBP lifecycle based on MIKE approach.

We also present the metrics related to $\mathrm{XBP}$ in order to provide tangible factors to evaluate the explanations of the model.

In order to achieve this objective, the following activities were carried out:

- Searching and selection of studies and papers about business process management, business process and business process lifecycle: this step included searching in international databases like Google scholar [5] and business process journals and conferences, also, some e-books have been included in order to study the history of business process development throughout the years in order to build a solid knowledge, espe-

\footnotetext{
${ }^{1}$ Model-based and Incremental Knowledge Engineering.
} 
cially the references that have considered mentioning business process relationship with explainability and transparency concepts, as well as its limitations.

To define the scope of this work, business process reengineering was also included, as some references presented process re-engineering as a solution for problems related to this research as well as process re-engineering.

This helped us refine the objectives and purpose of this work: our work does not consider process re-engineering, it focuses solely on dealing the as-is business processes, and the output is the same as-is model but with an added layer of explanations.

- Search and study papers and articles that present the concept of explainability as an abstract concept, with its definition and meaning in other fields: this step included studying research papers that show the use of explainability in different fields, the importance of using it and its limitations.

During this search, we have found some interesting articles and papers that introduced the explainability concept by using it in artificial intelligence, especially in machine learning, where a new model is built in order to generate explanations and to explain the reasoning behind every decision made by the artificial intelligence systems. This has been called Explainable Artificial Intelligence (XAI).

We also found that research in explainable intelligent systems dates back to 1985, under different names and titles, where the Explainable AI (XAI) is an initiative originated by DARPA ${ }^{2}$ in 2016 . The purpose of XAI presented in the DARPA XAI program [6] is to provide end users with an explanation of individual decisions, enable users to understand the system's overall strengths and weaknesses, convey an understanding of how the system will behave in the future and perhaps even how to correct the system's mistakes. During this search we have studied the XAI model, with its related framework, process, metrics, practical examples and limitations, which was the basic step that led us to the next step.

- In the previous steps, we gained knowledge in both concepts, in addition to a practical use of the explainability in AI. In parallel, we also searched for studies that considered using business processes with explainability, but unfortunately, we have not found anything related to this topic in specific.

- The search and study included an in-depth exploration of the MIKE approach, presented for the first time in 1998. We also looked for related papers that used this approach later on, in order to build the XBP lifecycle based on this approach.

- Finally, categorizing, alignment and analysis of the information found have been done, building the bridge between the two concepts and working towards a model of XBP, a framework, and a lifecycle and metrics building a base for future efforts in this topic.

\section{Literature Review}

\footnotetext{
${ }^{2}$ The Defense Advanced Research Projects Agency.
}

\subsection{Business Process Management}

Business Process Management (BPM) is defined as a collection of technologies capable of translating business process models into computer-supported activities, relinquishing routine management and control tasks from the organizational agents [7].

BPM focuses on pursuing the continuous improvement of the operational processes of an organization, promoting effective, efficient, transparent and agile performance, considering an operational or business process as a sequence of activities with an order of realization over time, which converts inputs given into output (a result, a product ...) using specific execution methods and with the support of adequate resources, adding value to the organization.

BPM became an integral part of IT infrastructures of modern businesses, to manage the design, configuration, enactment and diagnosis of their processes.

Every organization independently from its type or size must manage business processes [8].

\subsection{Business Process}

As BPM is defined as a body of methods, techniques and tools to discover, analyze, redesign, execute and monitor business processes, this definition reflects the fact that business processes are the focal point of BPM.

A business process is a collection of interrelated events, activities and decision points that involve a number of actors and objects and that collectively lead to an outcome that is of value to at least one customer. The literature provides a variety of definitions about business processes [1]; [2]; [9]; [8]; [10].

One of the most influential definitions is made by Davenport [2] who defines "process is simply a structured, measured set of activities designed to produce a specified output for a particular customer or market". Definitions by Hammer and Champy [1], Dumas et al. [8] and Burratin [10] share that the output of the process is of value to the customer and thereby emphasizing the general need of customer orientation.

It is important that the business process stays "up to date and as flexible as possible, in order to meet the market requirements and the business objectives" [10].

Rosemann et al. [11] show that companies need adaptive business processes which can be adjusted with the current dynamic environment to achieve competitive advantage.

In addition, companies need to continuously improve the performance and efficiency of their business processes [12]; [13]. Dumas et al. [8] define that the business process design affects both the quality of service of customer-facing processes and the efficiency with which internal services are delivered.

The design and the performance of business processes can become a competitive differentiator when a company has better processes than companies offering similar products or services [8].

Finally, the outcome is consumed by a customer. If the 
outcome is positive, then the customer receives value from it. In case the outcome is negative, the expected value is not received by the customer [8], [14].

\subsection{Business Process Lifecycle}

BPM implies a "permanent and continuous organizational commitment to manage the organization's processes" [15].

Dumas et al. [8] define a model that shows how a business process is managed by the BPM discipline through the BPM lifecycle. It defines six stages, through which a process is identified, discovered, analyzed, improved, implemented, monitored and controlled. In each stage there are methods, techniques and tools that support the application of BPM in an organization, and the most important artifact in all stages is the process model. These phases are:

- Process Identification. In this phase, a business problem is posed, processes relevant to the problem being addressed are identified, delimited and related to each other.

The outcome of process identification is a new or updated process architecture that provides an overall view of the processes in an organization and their relationships. In some cases, process identification is done in parallel with performance measure identification [8].

- Process Discovery (also called as-is process design). Here, the current state of each of the relevant processes is documented, typically in the form of one or several as-is process models. Processes are usually encoded as a visual process model, but they can also be described in structured or plain text format, or with the help of a computer simulation, or computer readable file. An as-is process model shows the current working process and a to-be process model shows the proposed process [16].

In this stage, process analysts use techniques to gather information in order to understand and document the innerworkings of a process as it currently exists, creating what is called an "As-is" model. This model is meant to be a tool for all further stages of the lifecycle, supporting them primarily by facilitating the communication of how the process is actually done between the process' stakeholders.

Therefore, it is important that this model be easy to understand. Although it is possible to model processes in a textual format, the ambiguity inherent in the medium and the difficulty in reading the text makes modeling using graphic diagrams a better option. Process models have many purposes, of which the most important one is the understanding of process, sharing of process knowledge and identifying and preventing problems. This is also a prerequisite for process analysis, redesign and automation of business processes [8], [17].

There are several notations for process modeling such as flowcharts, Unified Modeling Language (UML) activity diagrams (OMG, 2015), Unified Modeling Language Activity Diagram (UML AD), or Event-driven Process Chains (EPC) [18]. From these languages, two have been standardized by International Organization for Standardization, these notation languages are BPMN and UML AD [16], but, in the context of BPM, the standard notation is (BPMN) (OMG, 2011).

In BPMN there are five categories, which are flow objects, connecting objects, swim-lanes, artifacts and data objects [19].

- Process Analysis. In this phase, issues associated with the asis process are identified, documented and whenever possible quantified using performance measures. The output of this phase is a structured collection of issues. These issues are typically prioritized in terms of their impact and sometimes also in terms of the estimated effort required to resolve them [8].

- Process Redesign (also called process improvement). The goal of this phase is to identify changes to the process that would help to address the issues identified in the previous phase and allow the organization to meet its performance objectives. To this end, multiple change options are analyzed and compared in terms of the chosen performance measures [8].

This entails that process redesign and process analysis go hand-in-hand: As new change options are proposed, they are analyzed using process analysis techniques. Eventually, the most promising change options are combined, leading to a redesigned process.

The output of this phase is typically a to-be process model, which serves as a basis for the next phase [8].

- Process Implementation. In this phase, the changes required to move from the as-is process to the to-be process are prepared and performed. Process implementation covers two aspects: organizational change management and process automation [8].

Organizational change management refers to the set of activities required to change the way of working of all participants involved in the process. Process automation on the other hand refers to the development and deployment of IT systems (or enhanced versions of existing IT systems) that support the to-be process [8].

The executable process model is derived from the to-be process model and this executable model is deployed in a business process management system.

- Process monitoring and controlling. Once the redesigned process is running, relevant data are collected and analyzed to determine how well is the process performing with respect to its performance measures and performance objectives. Bottlenecks, recurrent errors or deviations with respect to the intended behavior are identified and corrective actions are undertaken. New issues may then arise, in the same or in other processes, requiring the cycle to be repeated on a continuous basis [8]. This process lifecycle is shown in Figure 1.

\subsection{Explainability}

In artificial intelligence, explainability is defined as the ability to explain or to provide the meanings in understandable terms to a human [20].

The state of explanation in artificial intelligence systems 


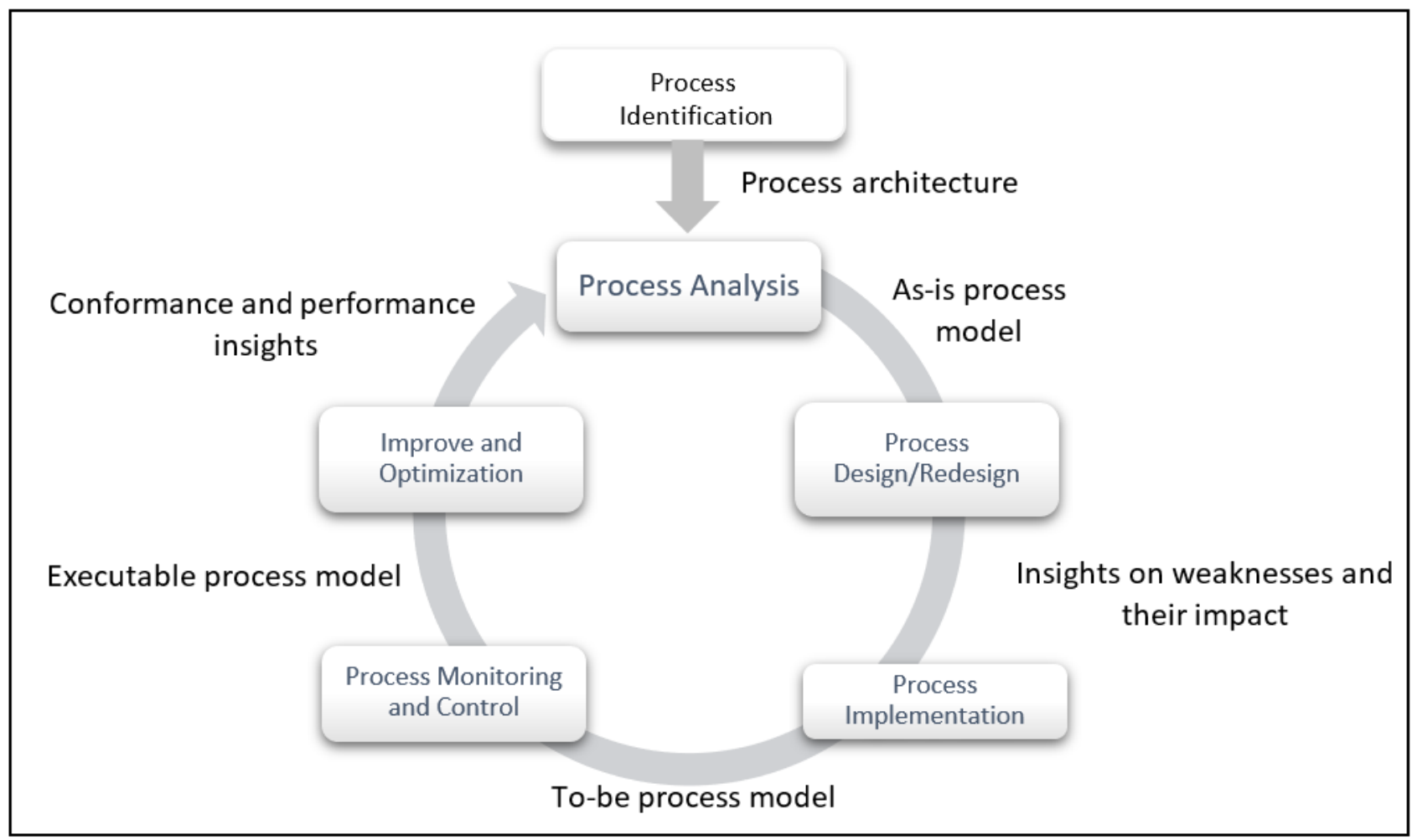

Figure 1. Business Process Lifecycle (Dumas et al.,[8])

has been reviewed extensively. It is generally agreed that "Enhancing the explanatory power of intelligent systems can result in systems that are easier to use and result in improvements in decision-making and problem-solving performance" [21]. Recent studies [22], have identified two types of explainability:

local and global explainability, for a particular model.

In local explainability, an explanation behind an individual decision or prediction is provided, while in global explainability only a single explanation is given. Local explainability can be given, for instance, with respect to the prediction related to the future of a specific trace. Besides explainability types, explanation techniques fall under one of two categories: ante-hoc and post-hoc.

In ante-hoc methods, explanation is given based on the same model and the explainability is incorporated into the model itself. Linear regression, decision trees, random forests and Bayesian deep learning are examples of it.

On the other hand, in post-hoc techniques, explanation is given based on different models. Another model is trained and used to provide an explanation for a specific local decision. LIME, SHAP, BETA, and Local Gradient Explanation are the most used examples of post-hoc techniques. There are several techniques and libraries that provide explanations for black-box models.

Historically, relevant research studies on causal reasoning relevant to explanation have been conducted [23]; [24]; [25]; [26] [27]; [28]; [29] [30] [31], and some papers have specif- ically investigated the reasoning behind events, entities and categories.

Although research on explanation is typically focused on the person (or system) producing the explanation, a critical aspect of this is whether the offered explanation has an impact on the individual who is the recipient or beneficiary of the explanation: Does the explainer understand the system, concepts, or knowledge?

Research in this area stems from work on understanding in general (e.g. [32]; [33]; [34]). Counterfactual reasoning is a central notion in some theories of explanation. Explanations should provide information about when, why and how effects or outcomes might change or be different (e.g. [35]).

Both causal understanding and the understanding of concepts often involve asking hypothetical counterfactual questions. Questions of the counterfactual from "What if?" and "What would happen if?" and questions in the contrastive form "You says it is X but why is it not Y?" represent the attempt of learners to explore the range of variation of categories and concepts and the causal structure of events.

Byrne et al. ([36]; [37]), Hoffman et al. [38] and Mandel et al. [39] have done some reviews on counterfactual reasoning. Other research focus on the Prospective (causal) reasoning, which is different from counterfactual reasoning: while the latter focuses on how things might or might not have been different if aspects of the past had been different, the former focuses on things that might or might not happen in the future [40]; [41]. 
Researchers have hypothesized that explanation is the search for answers to why, how and what-if questions and, as such, is a form of inference making [42] and the process of articulating the causes of phenomena or events. In other words, explanation and causal reasoning are co-implicative. Instances of explanation often are expressions of the causes of things [43]; [44]; [45] [30].

Another research states that the explanation of "why something is what it is" entails an explanation of "why it is not something else." In other words, explanation and counterfactual reasoning are co-implicative.

Instances of explanation often are expressions of counterfactual reasoning [37]. Koehler et al. [46]; Lombrozo et al. [47]; and Mitchell et al. [48] state that explanation of "why something is what it is" entails a prediction of "what might happen next." In other words, explanation and prospection are co-implicative.

Instances of explanation are often expressions of what will happen in the future. Ahn et al. [26] has examined the biases, errors and limitations that can occur during explanation explaining that people prefer causal explanations that refer to multiple causes when those causes are understood as a simple chain.

Giffin et al. [49] showed that concepts or categories that are referenced in the question to get an explanation can influence how people ascribe causes. In addition, the explanations people generate for everyday events and human affairs are often biased, in that people's lack of knowledge and susceptibility to misinformation leads them to create, value and prefer biased or incorrect explanations [50] [51].

Generally, users like to be provided with explanations, even if they are justifications of system operations expressed in somewhat formal terms [52]. That is why many researchers have proposed answers to the question of what makes for a good explanation. Einhorn et al. [53] and Hilton et al. [54] define that explanations are good if they make sense in terms of the context or the enabling conditions of cause-effect relations.

The process of explanation sometimes helps learners develop new concepts or conceptual categories, or revise their understanding of concepts they already know [55] and [56].

Unfortunately, most studies provide little or no detail concerning the exact elicitation and representation methods used, but generally speaking, researchers rely on one of two methods: either interviews (semi-structured or structured survey) or some sort of diagram creation task (e.g., influence diagrams, flow diagrams, etc.).

Various researchers have proposed taxonomies of kinds of explanations and principles composed from them. Many different kinds of representations are regarded as presentations of explanations. It is noted that an explanation can involve mixed types (e.g., a story with diagrams). Table 1 lists the kinds of representations that are regarded as explanations [57].

\subsection{Explainability and Business Process}

Unfortunately, most studies provide little or no detail concerning the exact relationship between business process and explainability. Some work has been done discussing the role of AI in Business Process Reengineering, where Yu et al. [3] developed a framework for modeling and analyzing organizations in support of several applications, including business process reengineering.

The framework views processes as involving social actors who depend on one another for goals to be achieved, tasks to be performed and resources to be furnished. The framework includes two models:

- Strategic Dependency Model, which describes the network of relationships among actors;

- Strategic Rationale Model, which describes and supports the reasoning that each actor has about its relationships with other actors.

Yu et al. [3] discussed the Strategic relationships redesign tool that is based on the Strategic Rationale Model where the basic idea of the tool is that one can obtain an understanding of the why behind process elements (or steps) by following (querying) their links to process design goals (up the means-ends hierarchy), extending the Strategic Rationale Model when appropriate.

Also, in this same study, Yu et al. [3] presented another tool, the Qualitative reasoning support, which is adapted from work by Chung et al. [58]. This is essential in supporting business process redesign while adding rationale during this phase.

Hamscher et al. [59] discussed having at least two distinct roles for AI in BPR. One role is as an enabling technology for reengineered processes. A second, less common but potentially important role is in tools to support the change process itself.

Verenich et al. [60] discussed the Explainable Predictive Monitoring of Business Process discussing the use of process mining with explainability that presented four major points: - Explaining how the model makes certain predictions;

- Directly designing a transparent classifier that solves the same classification problem which is known as "Transparent Box Design";

- Providing an explainable predictive process monitoring method by automatically discovering a BPMN process model from the event log;

- Providing an application of the proposed explainable predictive monitoring methods to improve the efficiency of business processes.

This work has been presented based on two other related research studies: Schneider et al. [61] discussed the major drawback of black-box prediction methods in practical deployments is that users have difficulties trusting the prediction when the reasoning behind the prediction is unclear and in real-life applications, users do not only need to get predictions, but they also need to be able to act upon these predictions.

In turn, to do so, users need to understand the rationale 
Table 1. Table of Format and Reference in explanations (Muller et al. [57])

\begin{tabular}{|c|c|}
\hline $\begin{array}{c}\text { Format } \\
\text { (How it is expressed) }\end{array}$ & $\begin{array}{c}\text { Reference } \\
\text { (What it is about) }\end{array}$ \\
\hline $\begin{array}{l}\text { - } \text { Visualizations (e.g., Heat maps) } \\
\text { - Text (Statements, Narratives or Stories, } \\
\text { - } \text { Answers to queries, Human-machine dialogs) } \\
\text { - Matrices) } \\
\text { - Conceptual Process Models (Diagrams) } \\
\text { - Graphs, Networks } \\
\text { - Tables } \\
\text { - Abstractions, generalizations } \\
\text { - Timelines } \\
\text { - Hierarchies (Trees) }\end{array}$ & 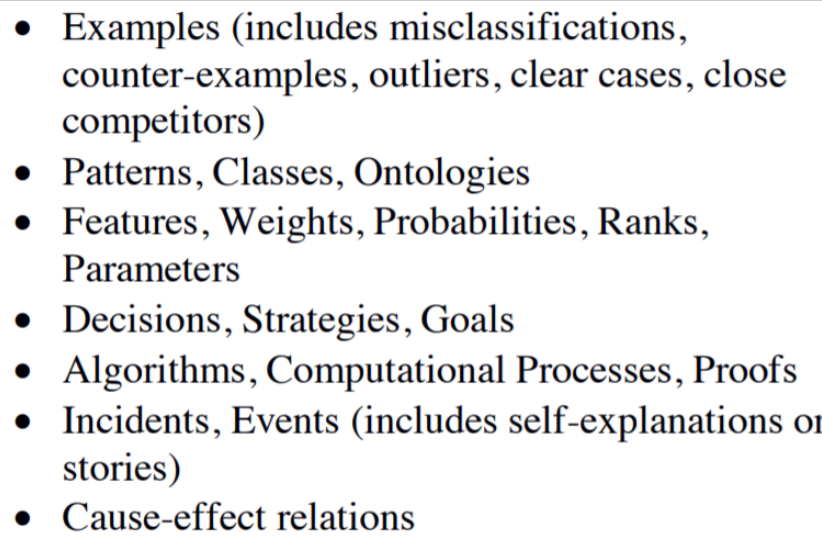 \\
\hline
\end{tabular}

for these predictions. The decision on how to respond to a prediction is largely driven by the user's interpretation of the predictive model's decision logic. If this interpretation matches the intuition of a human decision maker, it might enhance trust in the model.

Guidotti et al. [62] presented a survey to provide a comprehensive review of methods for explaining black-box models, as well as a taxonomy of explainability methods according to the type of problem faced.

Recent research study by Harla et al. [63] presented explainable predictive business process monitoring using gated graph neural networks, where they provided a technique that makes a prediction more explainable by visualizing how much the different activities included in a process impacted the prediction. According to their study, they were the firsts to use gated graph neural networks (GGNN) to make decisions more explainable.

Regarding the relationship between explainability and business process modeling and as in any modeling effort, formulating the model requires committing to the particular reasoning tasks it is expected to support. Toronto virtual enterprise (TOVE) project [64] uses the notion of advisers each with a particular perspective on the enterprise to inform and constrain the modeling effort.

Modeling and analysis of business processes is part of the broader task of designing a new business process, that is, tools for evaluating designs formulated by humans.

As we have presented in the literature review, we have not found, to our knowledge so far, any work done in the exact topic of applying explainability to business processes.

\section{MIKE Approach}

\subsection{Introduction}

The MIKE (Model-based and Incremental Knowledge Engineering) approach has been presented by Angele et al. [65] for developing knowledge-based systems.

MIKE integrates semiformal and formal specification techniques together with prototyping into a coherent framework. All activities in the building process of a knowledge-based system are embedded in a cyclic process model.

The approach uses a formalism which serves as a communication basis between expert and knowledge engineer during knowledge acquisition. The semiformal knowledge representation is also the basis for formalization, resulting in a formal and executable model specified in the Knowledge Acquisition and Representation Language.

This language is executable, the model of expertise can be developed and validated by prototyping. A smooth transition from a semiformal to a formal specification and further on to design is achieved because all the description techniques rely on the same conceptual model to describe the functional and non-functional aspects of the system.

Thus, the system is thoroughly documented at different description levels, each of which focuses on a distinct aspect of the entire development effort. Traceability of requirements is supported by linking the different models to each other.

\subsection{MIKE Lifecycle}

Within the entire development process, a large gap has to be bridged between the informal requirements and human knowledge on the one hand and the final realization of the expert system on the other hand. Dividing this gap into smaller ones reduces the complexity of the entire modelling process because in every step, different aspects may be considered independently from other aspects. 
Therefore, in MIKE the entire development process is divided into a number of sub-activities, where each of these activities deals with different aspects of the entire development: Elicitation, Interpretation, Formalization/Operationalization, Design and Implementation.

The knowledge acquisition process starts with Elicitation. i.e. trying to get hold of the experts' knowledge. Methods like structured interviews, observation, structuring techniques, etc. The resulting knowledge expressed in natural language is stored in so-called knowledge protocols.

During the Interpretation phase the knowledge structures which may be identified in the elicitation model are represented in a semi-formal model. All structuring information in this model which is called the Structured Model, like the data dependencies between two inferences, is expressed in a fixed, restricted language while the basic building blocks, e.g. the description of an inference, are represented by unrestricted texts.

The Structure Model is the foundation for the Formalization/Operationalization process which results in the formal Expertise Model. The expertise model has all decisions and functional requirements which have been represented as natural language texts are here expressed in the formal specification in order to avoid the vagueness and ambiguity of natural language descriptions and thus help get a clearer understanding of the entire problem-solving process.

During the Design phase, additional non-functional requirements are considered. These include e.g. efficiency, maintainability, robustness, portability, etc., but also the constraints imposed by target software and hardware environments. Thus, the Design Model captures all functional and non-functional requirements, decisions and activities with their explanations.

In the Implementation phase, the Design Model is implemented in the target hardware and software environment. Experts can be integrated into the process at all phases.

Every cycle produces a prototype of the expert system which may be evaluated by testing it in the real target environment. The results of the evaluation are used in the next cycle to correct, modify, or extend this prototype as figure 2 shows.

This process is continued until all requirements are fulfilled.

\section{Explainable Artificial Intelligence (XAI)}

\subsection{Introduction}

Explainable AI (XAI) is an emerging branch of AI where AI systems are made to explain the reasoning behind every decision made by them.

The research for explainable intelligent systems dates back to 1985 and the Explainable AI (XAI) is an initiative originated by DARPA ${ }^{3}$ in 2016.

\footnotetext{
${ }^{3}$ The Defense Advanced Research Projects Agency.
}

\subsection{XAI Concept}

The target of XAI is an end-user who depends on decisions, recommendations, or actions produced by an AI system and therefore needs to understand the rationale for the system's decisions.

For example, an intelligence analyst who receives recommendations from a big data analytics algorithm needs to understand why the algorithm has recommended certain activity for further investigation. Similarly, a test operator of a newly developed autonomous system will need to understand why the system makes its decisions so that he/she can decide how to use it in future missions.

The XAI concept provides end users with an explanation of individual decisions, enables users to understand the system's overall strengths and weaknesses, conveys an understanding of how the system will behave in the future and perhaps how to correct the system's mistakes [6], as illustrated in figure 3.

\subsection{XAI Framework}

XAI mainly answers the questions of Why? Why not? What for? and How? Which brings the concepts of Understanding and Trust into consideration [66]. Arrietaa et al. [67] state that these questions also address other elements behind the need for explainable models, such as Causality, Transferability, Informativeness, Fairness and Confidence. XAI is structured into three related research streams:

- How to produce more explainable models;

- How to design the explanation interface; and

- How to understand the psychological requirements for effective explanations.

An XAI system consists of an explainable model and an explanation interface. XAI system takes a task as input to the explainable model outputs a decision, a recommendation, or an action to the end-user as well it provides explanations to the user that justifies the decision, recommendation or action. The user can thus make a decision based not only on the system's suggestion, but also on the explanation provided by the system. The XAI framework and how the XAI system works is presented by Gunning et al. [6], and illustrated in figure 4.

\subsection{XAI Process and Metrics}

Explanations generated by XAI can be evaluated in terms of criteria related to user performance. User comprehension of explanations can be assessed and the results correlated to qualities of their mental models and to their performance. The measures roughly represent increasing difficulty and sophistication. The most basic capability would explain a model's individual decisions.

A more advanced capability would explain the strengths and weaknesses of the overall model. The most sophisticated capability would enable the user to identify and correct mistakes. It may not be possible to achieve all of these desired capabilities, especially the capability to correct mistakes, 


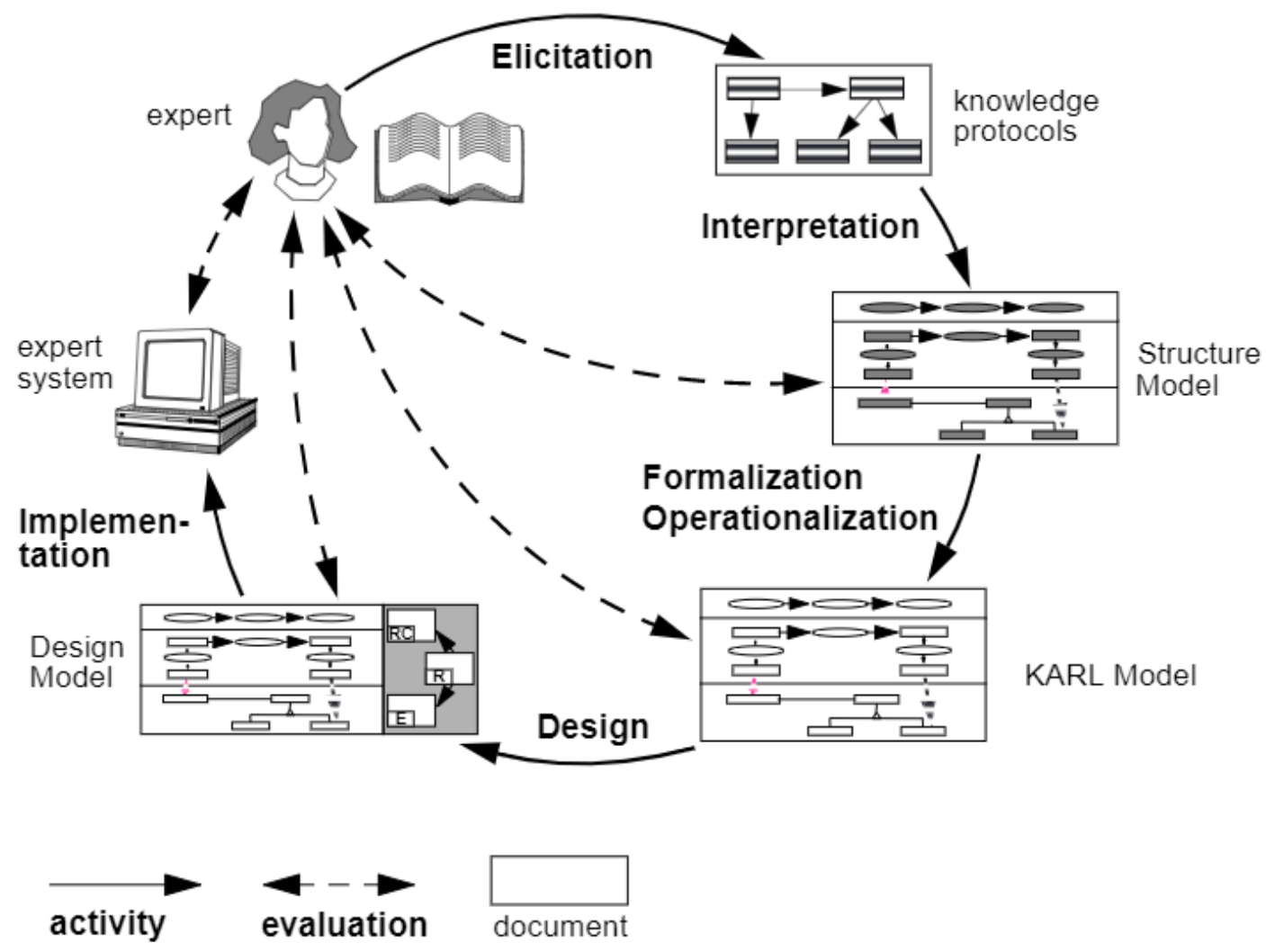

Figure 2. MIKE Lifecycle (Angele at al. [65])

which would be beyond the reach of most current machine learning techniques.

The conceptual model used in the DARPA XAI program shows the place and role of different classes of measures in the evaluation of the XAI system and the Human-XAI system performance.

In this model, explanations should induce better mental models and performance, which produce appropriate trust in the system $[68]^{4}$. This conceptual model is shown in figure 5 .

\section{The Explainable Business Process (XBP)}

\subsection{Introduction}

The Explainable Business Process (XBP) takes XAI as a reference, and brings it together with the concepts of business process lifecycle and the MIKE approach to provide a structure and lifecycle for the XBP. To measure the explanations, we suggest referencing the XAI metrics.

\subsection{The Approach of Explainability and Business Process}

We map the relationship between the concepts of explainability and Business Process and the overlaps between them. We

\footnotetext{
${ }^{4}$ A detailed presentation on methods for measuring explanation appears in another DARPA XAI Report (Hoffman et.al, 2018)
}

have included the system interface in this diagram as well, considering that the execution of the business process will be through a system, where end-users can interact with the business process through this system interface.

The intersection between explainability and business process is the explainable model that includes the explanations added to the business process and the intersection between the explainability and the system interface is the explanation interface where the explanations will be displayed to the users in order to execute the business process.

The intersection between business processes and the system interface is the interactive business process where the business process can be executed by users by using the system interface (for example, software). Finally, we can state that $\mathrm{XBP}$ is in the intersection between these three concepts in order to have the XBP model as executed and interactive, as shown in figure 6.

\subsection{The XBP Framework}

Based on the XAI framework discussed in Figure 4 in the previous section, we define an Explainable Business Process (XBP) framework that consists of two main components:

- An explanation model: this model is the part that includes the explanations provided by the human experts who are responsible for the business process and own the knowledge about the business process, including the reason behind the 


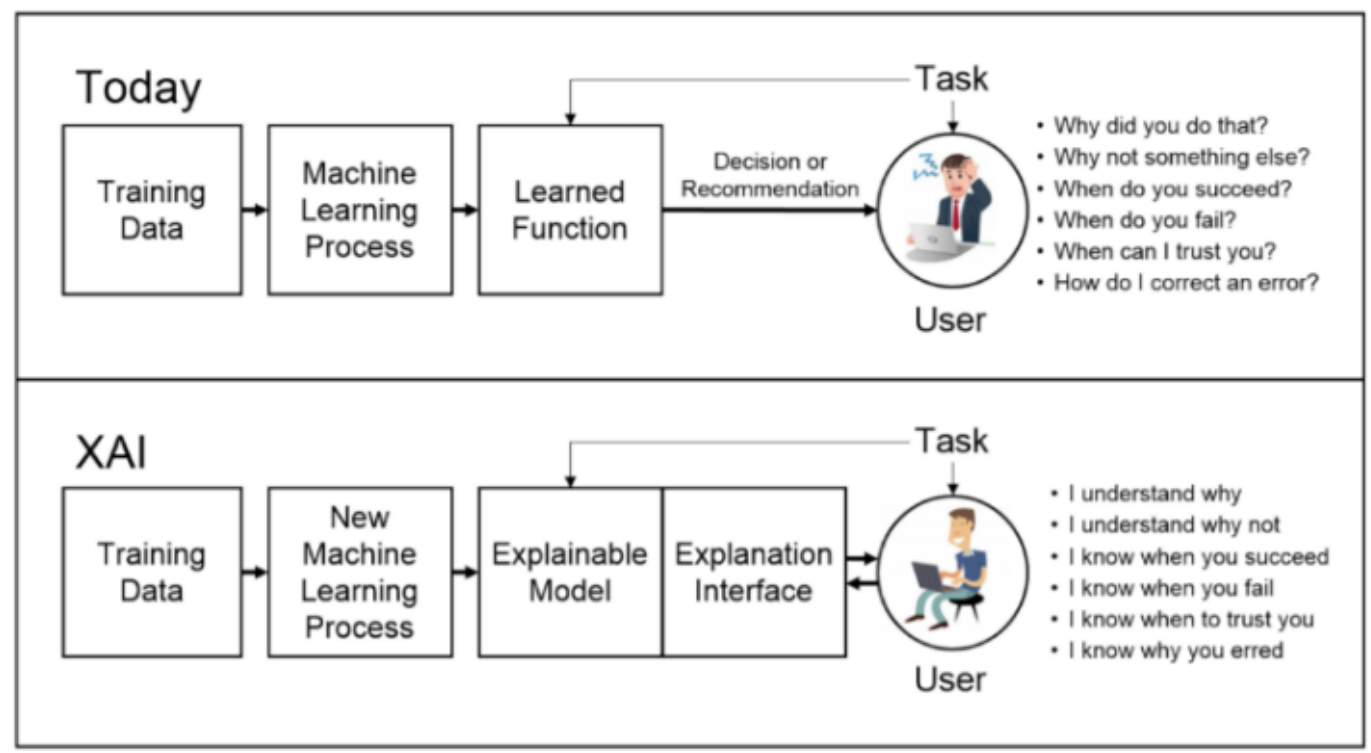

Figure 3. XAI Concept (DARPA XAI Program [57])

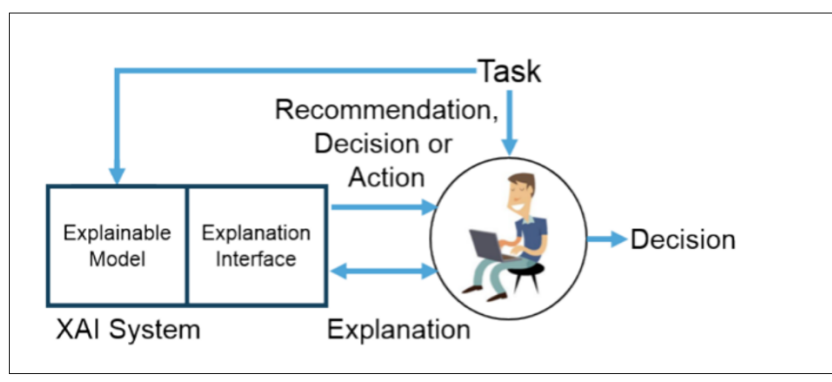

Figure 4. XAI Framework (DARPA XAI Program [57])

business process, its activities, decisions, rules and the intentions of each requirements and behavior of the business process;

- An explanation interface: this component is the part that presents the interface that displays the explanations to the end-users who will interact with the business process, where explanation will be provided to the user and receive his feedback or more explanation from the user's point of view or experience.

Together, they make up what is called the Explainable Business Process (XBP).

This can be added to any existing business process to deliver the desired output by allowing the user to take the proper action based on a transparent and clear knowledge that increases the user's comprehension and decreases the ambiguity of the business process details.

Compared to XAI, which has a model that generates explanations, the explanation model of the XBP can be built by adding a predefined set of explanations provided by human experts to the business process as a whole and to its decisions and actions in specific ways.

Although the explanation model is linked to the explanation interface, we suggest that the explanations should be added to the business process during the modeling phase of the business process lifecycle as annotations in order to carry this knowledge on to all the phases after that, developing a continuous cycle of improvement for the explanations that have already been added, or even adding more explanations in each cycle, either based on changes to the business environment, or to legal constraints or on any other kinds of changes that affect the decisions and activities in the business process, as well as the explanations provided from the end-user generated by the users experience or demands of new or special cases.

This leads us to logically divide the XBP in three main stages as the following:

- Build Explanations by human experts for the business process as a whole and the decisions made, activities and actions as parts of it;

- Add an explanation layer to the business process in the modeling phase of its lifecycle to build the explanation model;

- Display explanations to users using an interface where users are able to receive and give back feedback, make new demands or add more explanations.

Finally, a user will be able to take the proper action and decision in an understandable, explainable and, most importantly, transparent way, as illustrated in figure 7 .

In order to show the connection between domains in the proposed concept and which part of the XBP conceptual model was taken from which domain, we present an overview of the conceptual model highlighting the main domains that are presented in the model which they are BPM as the domain which BP comes from, XAI as the reference we based our model and the metrics of the model on and MIKE approach as the approach we considered to represent XBP lifecycle .

We also show in the map the explanation interface which the explanation model uses so the user can execute the busi- 


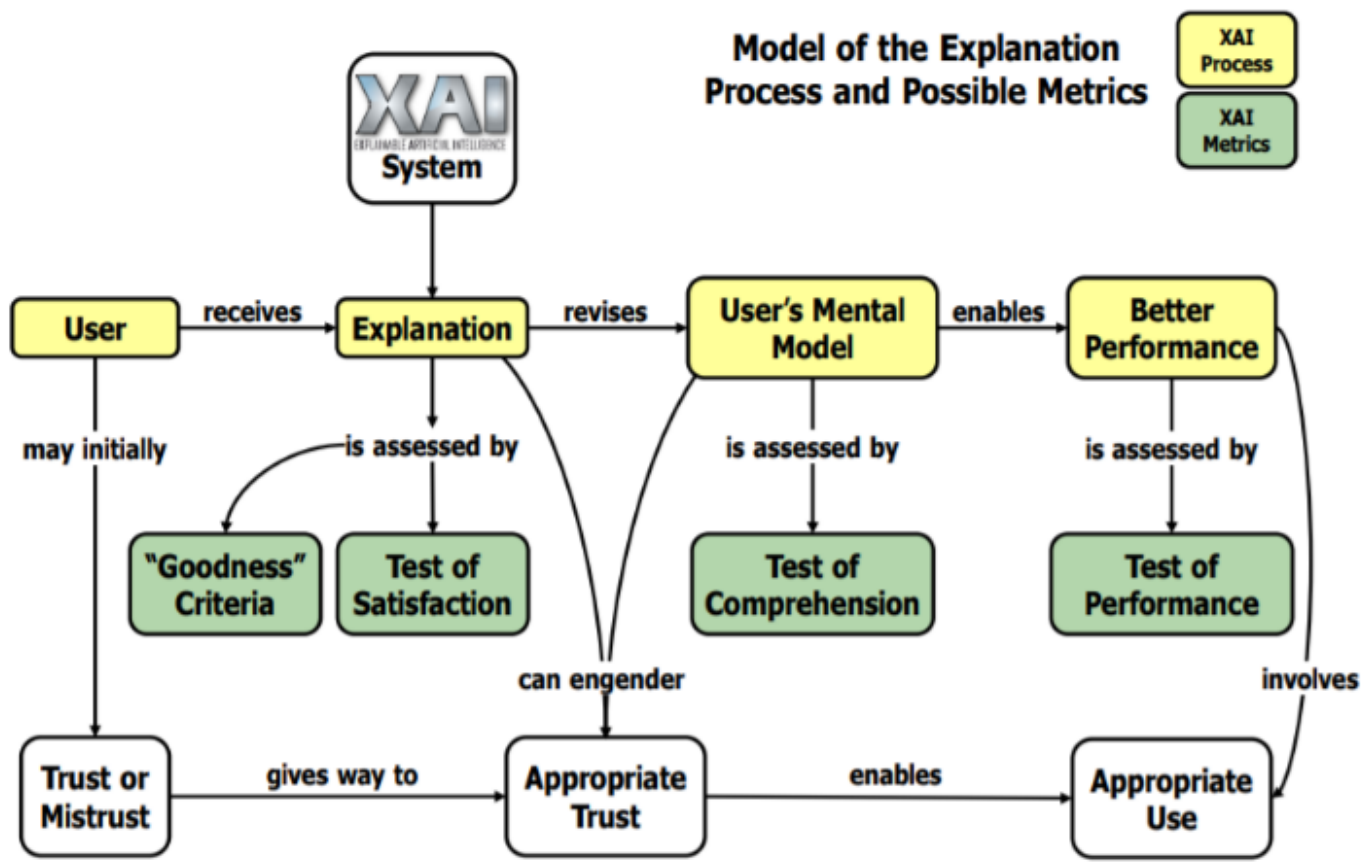

Figure 5. A conceptual model of the process of explaining, in the XAI context (DARPA XAI Program [57])

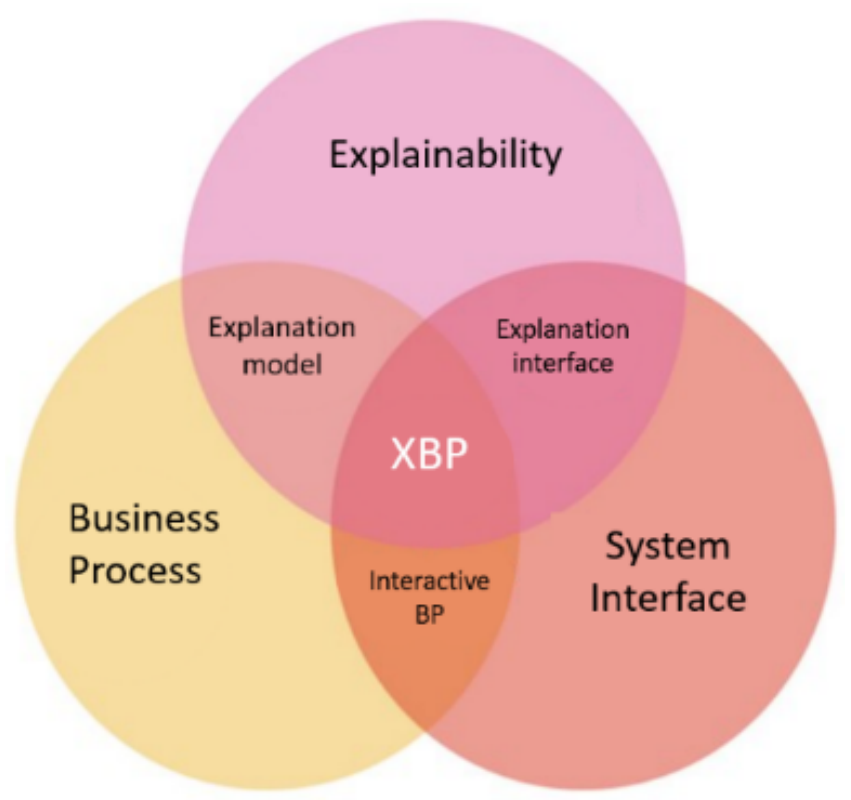

Figure 6. Venn Diagram for XBP

ness process and interact with its explained activities and decisions. Also, we show the knowledge domain which both explanations provided from human experts and MIKE approach depend on. The map in Figure 8 shows the relationships between the entities and categorizes them visually by using different colors for each domain.

\subsection{XBP Lifecyle}

Based on the lifecycle of business process, we suggest adding the explanation layer in the modeling phase (the design phase) on the as-is model without suggesting any changes to the model to the to-be model, but only to provide the reasons and the needed explanations to the process, where we also take into consideration the MIKE approach, which achieves the concept of carrying the knowledge through the phases of the process.

MIKE provides the sub-steps that define the output (document) of each phase and we can find that the Formalization/Operationalization phase that results the model of expertise (MoE) gives more specific position between the structured model and the design model (more detailed place between the analysis phase and the implementation phase of the business process lifecycle), where the explanation layer could be presented in the XBP framework in its proper place.

The Formalization/Operationalization phase provides a representation that avoids the vagueness and ambiguity of natural language intentions, because the explanations provided by the human experts have to be interpreted, the formalization helps to get a clearer understanding of the entire process and its activities, to answer WHY this decision has been taken in a specific way rather than another way for example. This formalized MoE, which presents in this phase the defined, structured, formalized and informative explanations, can be directly mapped to an operational representation which bridges the large gap between explanations of the human expertise on the one hand and an executable business process on the other hand.

From the suggested XBP lifecycle, we present that structuring the business process can be done based on the elicitation model which includes all the requirements specifications of the process including the business rules, decisions, the logical flow of the process, etc. 


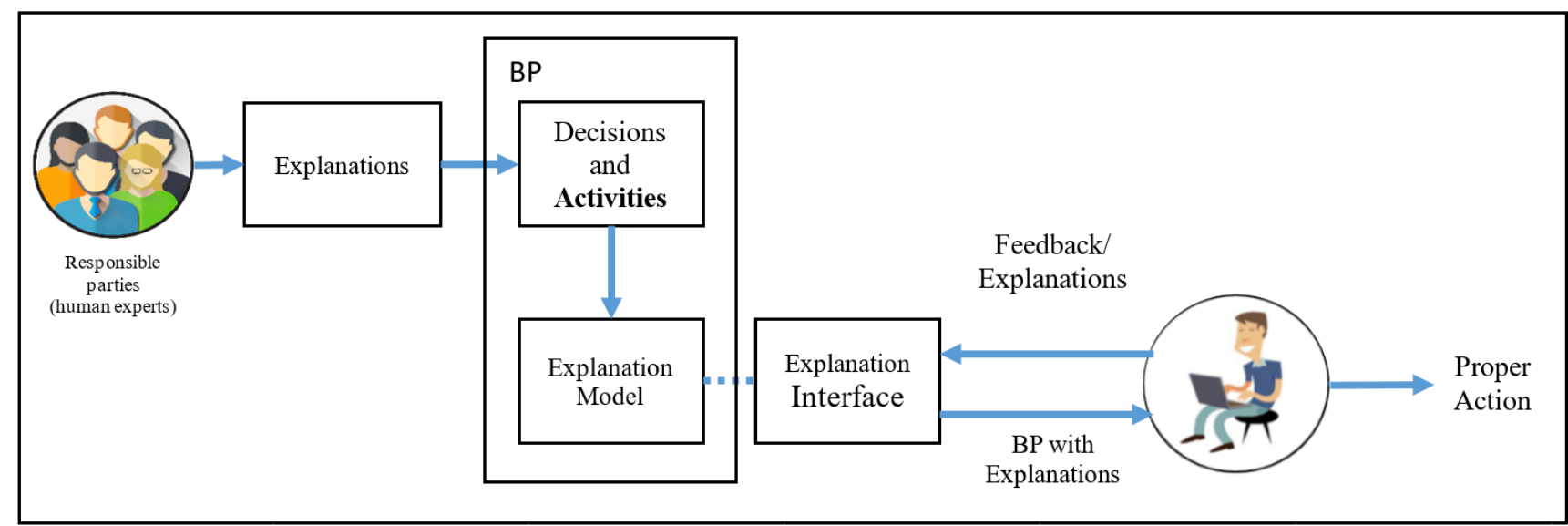

Figure 7. The Explainable Business Process (XBP) Framework

While the structure model holds the output of the elicitation phase in a structure form, yet the human experts' knowledge needs to be formed in the shape that carry the explanations to more structured and defined model which is done during the formalization phase and this should be done exactly before building the design model of the process where the annotations can take place based on the former model of expertise (MoE) and to be executed after that.

Although the expert/s have the main role of building and evaluating the models of the process, they also have the role of building the explanation layer on the formalization phase considering that they are the source of human knowledge and intentions who can best provide the rationale behind the process decisions and activities.

The end-user interacts with the process to get the desired outcome as well as providing feedback in order to ensure more engagement with the process and user satisfaction with the outcome, as well as more explanations, if needed. Figure 9 shows the adaptation of the MIKE model to XBP.

\subsection{XBP Process and Metrics}

The effectiveness of the explanations in the explanation model of XBP is a main factor of the effectiveness of XBP, where explanations should increase user satisfaction by being clear and useful and improving the mental knowledge by justifying the decisions of the process and the overall process, as well as helping users to understand the current activity, predict the next intervention, increase performance, support user's decision and increase user's trust in the process. In addition, there should be a possibility to extend the use of the explanations for identifying and correcting errors and continue improving the explanations.

Based on the measures explained in Section 5 and as Figure 5 shows the XAI metrics, we propose to consider the following metrics to evaluate the explanations provided by the human experts and added to the business process:

- Appropriateness/Goodness: to measure the users' judgment as to whether or not the explanation is good and sufficient for them and how "good" the explanation is on a certain scale;
- Satisfaction: to measure the degree to which users feel that they are satisfied with the explanations provided to them that will affect their actions;

- Comprehension: to measure the degree to which users feel that they understand the explanations provided to them and how easy they are to make the business process transparent; - Mental Model: refers to a user's knowledge before knowing the explanation;

- Performance: to measure the degree of efficiency of the process with the explanations comparing to the process without explanations, based on users' feedback;

- Trust: the subjective attitudes of users toward the process before and after explanation. Figure 10 shows these metrics.

\subsection{Explanations and Business Benefits}

Explanations can answer the following questions:

- Why does the workflow do that?

-Why does this activity do something and not something else?

- Why has this decision been taken and why is this other decision not considered?

-What information makes the business process more efficient/ successful?

- What information made the business process more inefficient/ failed?

- What information gives enough confidence and trust in the decisions made?

Possible business benefits to the enterprise by considering XBP are:

- Improving Business Process performance as the explanations help pinpoint issues in data and workflow;

- Making better decisions, as explanations provide extra information and transparency to the actions and activities;

- Giving a sense of control as the business process owner clearly knows levers for business process behavior and boundary;

- Giving a sense of safety as each decision can be subjected to safety guidelines and alerts on its violation;

- Building Trust with stakeholders who can see through the reasoning of each and every decision made; 


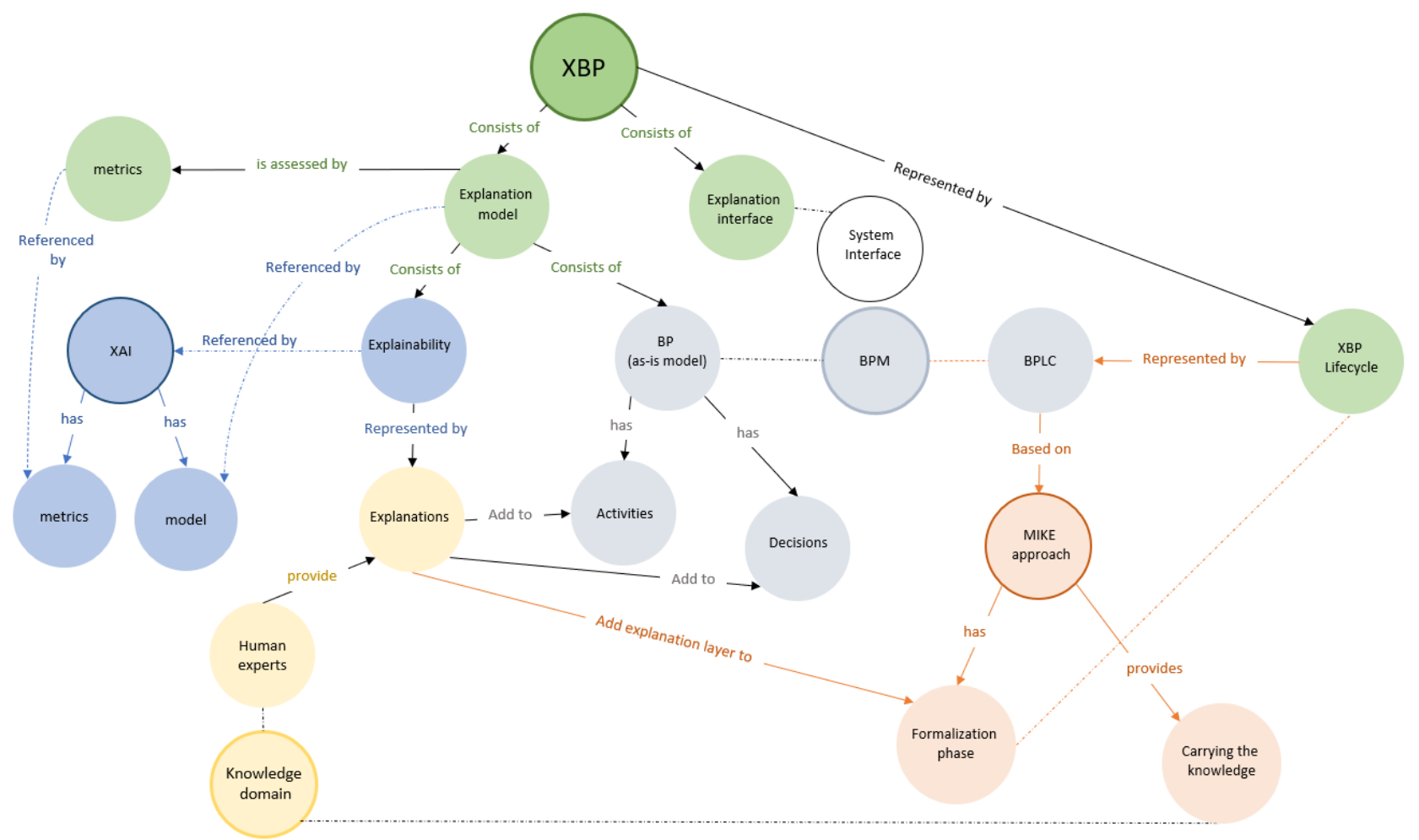

Figure 8. XBP Map of Concepts, Domains and Relationships

- Creating a better mechanism to comply with accountability requirements within the organization for auditing and other purposes;

- Increasing adherence to Regulatory requirements where 'Right to Explain' is now a must-have for a business process.

\subsection{Examples of XBP in real-life}

The importance of providing explanations to business processes is a user's demand to interact with the business process in an effective way. The following scenario is an example of using XBP in real-life.

In the scenario, a student wants to get the university student card to borrow books at the university library, access university buildings around campus and get student discounts on products and services. The student searched for the card emission process and she/he finds the steps as the following:

- Student must have an active enrollment;

- Student must upload a photo: this step has specific requirements (3X4 size, JPEG format, show complete head and neck, natural expression no smiling or frowning, without glasses, white background, 6 months recent, no hair cover eyes, without hats, without filters);

- Students must fill out a forum: this step has mandatory fields to fill in like (address, phone number, nationality). There are also other optional fields like (military status for males, voting information) and fields that are uneditable and already filled in (first name, last name, parents' names, student enrolment number);

- Analyze photo: this step takes 3 months to be approved or disapproved;

- To receive the card: you should send an email to the secretary after 3 months asking about the card readiness date, then you will be able to obtain your card once you are on campus at the students' center;

- To renew card requirements: you must upload a new photo following the photo guideline and updating the old forum.

The student logs into the system to upload the photo and submit the forum and she/he begins to have many questions about the reason behind some specific requirements for example:

- Why can't I upload a photo wearing my eyeglasses or hats?

- Why is my voting information requested optionally in the forum?

- Why should the background be white, why not plain or lightcolored background?

- Why does the decision of photo approval take 3 months?

- Why can't I receive my card at the post office or my address?

- Why does the photo have to be 6 months recent?

- What is the reason behind re-uploading a new photo and updating the forum to renew my card?

These questions can vary depending on the student's need to understand the reasons. Instead of sending maybe tone of emails to the secretary or searching on the university website or even asking other students who already got their cards about the reasons behind these activities and decisions of the process, the student can find the explanation for each requirement while she/he is following the process steps and these explanations can be represented in different formats as 


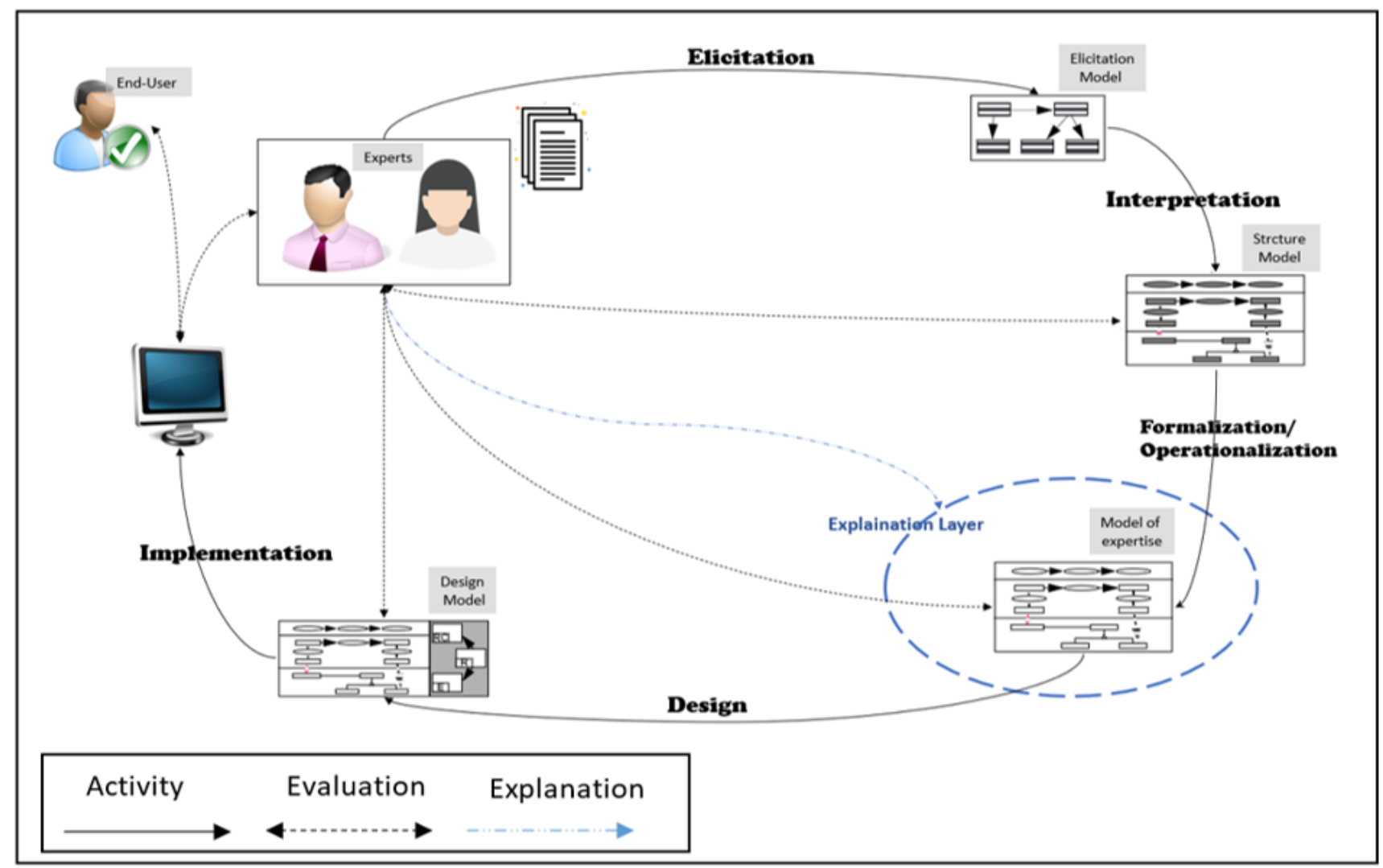

Figure 9. The XBP Lifecycle (based on MIKE approach)

mentioned in table 1 i.e. text, diagrams, tables, timeline or even multimedia.

The added explanations to the process activities and decisions that let the student understands the reason behind each requirement can be like the following:

- Smiling, wearing eyeglasses and hats affect facial features recognition;

- Voting information is optional for foreigners, buts it is mandatory for natives and it is requested because the voting number appears on the card due to university policy imposed by country law;

- White background is important for skin color as part of facial recognition;

- Photo approval decision is made by another organization and might be reviewed manually as an extra step;

- The service of sending cards to post offices or students addresses is not available at the university;

- The photo should be recent to reveal any changes like facial tattoos, surgeries or new facial marks;

- To renew the card, your photo must be 6 months recent to reflect the current appearance and updating the forum is a must to get updated information in case of change address, phone number, etc. or to fill out new mandatory fields.

After providing the students with explanations to execute the process, students will be able to understand what and why they should provide as an input.
To evaluate the explanations, student is asked to answer a survey to give feedback about the explanations as the following:

- Rate the overall quality of the explanations and rate each explanation (the goodness factor);

- Rate your overall satisfaction with the explanations (the satisfaction factor);

- Rate your overall comprehension of the explanations (the comprehension factor);

Provide us with your suggestions, problems and comments and if you have more explanations you would like to submit.

In the following step, the university technical team (business analyst, process analyst, process engineer, etc.) collects the students' feedback to be analyzed or solved and after that to create proper explanations and add them to the explanation model.

The technical team also measures the degree of efficiency of the process with the explanations than without it and calculates the percentage of the number of successfully completed requests to the total number of attempted requests.

In our example, not only the inbound enquiries to the responsible party (the secretary in our example) will be reduced, but also the ambiguity of the activities and decisions of the process will be minimized. Moreover, students will provide better input that increases the process efficiency without the need to do many failed attempts that lead to frustration or lack 


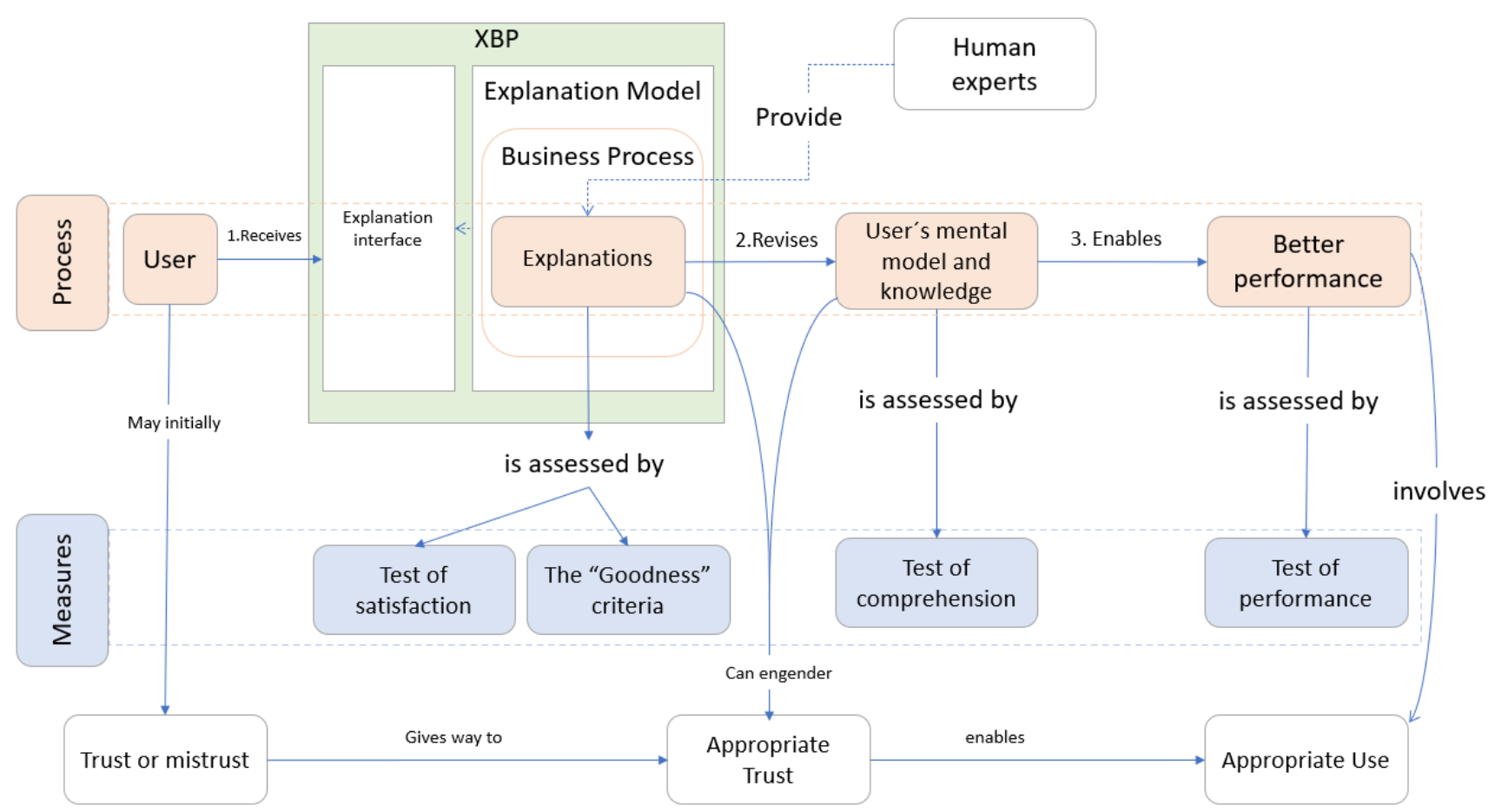

Figure 10. A conceptual model of the explaining process in XBP context and its metrics

of trust.

The examples of adding explanations to the business process can vary based on the business process itself, where each model can be specific based on the nature of the process.

\section{Discussion}

We discussed in this paper the possibility of bringing in the explainability concept to be applied to the business process. We presented a conceptual model that suggests adding an explanation layer to the business process model based on providing the rationale behind its activities and decisions, which results in what we called the Explainable Business Process.

We based our proposed concept on XAI as a reference for the explanation model in our model and the metrics to measure the explanations effectiveness in the model.

To show how this application be done, we presented the suggested lifecycle of XBP based on MIKE approach where the phase of formalization phase is defined in this approach where we suggest to add the explanation layer and for the value that MIKE approach provides in carrying the knowledge through the process, which is in our model, the explanations and reasoning knowledge provided by human experts.

Although the model provides some business benefits like decreasing ambiguity of the process and increasing trust and effectiveness in executing the process from end-users' side, setting and analyzing appropriate explanations, adding an explanation layer to the business process activities and decisions, building the explanations model, and evaluating the explana- tions continuously to make improvements to the model may increase complexity and add cost to the business process.

Cardoso [69] states that the four types of complexity in business process are Activity Complexity, Control-flow Complexity, Data-flow Complexity and Resource Complexity. Since our model does not increase the number of activities a process has, the model does not increase complexity of business process for this type. The model does not impact the business process control-flow complexity, as this type considers splits, joins, loops, and ending and starting points in the process. The data-flow complexity of a process increases with the complexity of its data structures, the number of formal parameters of activities, and the mappings between activities' data, and in our model, explanations are considered as data that is added to the process activities and decisions, but explanations themselves do not have any relationship between them, each explanation is dedicated to provide rationale behind an individual activity or decision, and in this case our model does not add any complexity to the process for this type. Activities in a process need to access resources during their executions. A resource is defined as any entity (e.g., human resources) required by an activity for its execution, such as a document or an explanation in our model. Our model might increase complexity for this type and it adds an extra cost to the process activities and decisions but it decreases cost in achieving the desired output of the process. 


\section{Future work}

We have presented in this study the conceptual framework of the XBP, where an empirical study can be done in order to put this conceptual model into practice, to evaluate the use of $\mathrm{XBP}$ in an existing business process and study the difference that XBP provides to the process comparing to execution of the business process without it and measures the output in terms of user satisfaction and process effectiveness.

Our example scenario can be put into practice by running an experiment for an actual student card emission process at a specific university and to interview both students and process experts to build the same process with explanations and compares the students feedback after executing the process with explanations to the process without explanations and finally to evaluate the explanations based on students feedback.

Another potential future work is to study the XBP in a collaborative environment to study the collaboration between human experts to collect, prepare and analyze explanations to build the explanation model. Further study might consider also the end-user explanations and feedback and study this part in the same collaborative environment.

Types and formats of explanations might have an impact on the process efficiency and user satisfaction, for example, explanations provided as multimedia might deliver the value better than the explanations added as text.

\section{Conclusion}

We explored in this paper the possibility of bringing the explainability concept to business process world to build a model that provides the rationale behind business process and its decisions and activities and we presented a fundamental concept of the explainable business process (XBP) and suggested the conceptual framework and XBP lifecycle, based on XAI and MIKE approach.

We presented the possible measures of the explanations' effectiveness and explained what kind of questions can be answered in the XBP and mentioned some business benefits of using XBP in organization. We provided an example of a scenario about student card emission process and discussed the explanations and metrics to measure them in the model. Model complexity and its impact on process complexity was one of the points we discussed in this paper and we suggested some ideas for future work.

\section{Author contributions}

Riham Alhomsi: Conducting the literature review, deriving and adapting the new models, writing initial writeup. Adriana S Vivacqua: Original idea, defining the concepts, supervising the research, checking models for consistency, revising/writing after initial writeup.

\section{References}

[1] HAMMER, M.; CHAMPY, J. Reengineering the Corporation: A Manifesto for Business Revolution. Business Horizons, Amsterdam, v. 36, p. 90-91, fevereiro de 1993.
[2] DAVENPORT, T. Process Innovation: Reengineering Work through Information Technology. Cambridge: Harvard Business Review Press, 1992.

[3] YU, E.; MYLOPOULOS, J.; LESPÉRANCE, Y. AI models for business process reengineering. IEEE Expert, Washington, v. 11, p. 16-23, setembro de 1996.

[4] GUIDOTTI, R. et al. A Survey of Methods for Explaining Black Box Models. ACM Computing Surveys, New York, v. 51, p. artigo 93, fevereiro de 2018.

[5] ACHARYA, V. Google Scholar. 2020. Disponível em: $\langle$ scholar.google.com $\rangle$.

[6] GUNNING, D. DARPA's explainable artificial intelligence (XAI) program. In: IUI '19: INTERNATIONAL CONFERENCE ON INTELLIGENT USER INTERFACES, 24., 2019, Marina del Ray. Proceedings of the [...]. New York: Association for Computing Machinery, 2019. p. artigo 2.

[7] ANTUNES, P.; aO, H. M. Resilient Business Process Management: Framework and services. Expert Systems with Applications, Amsterdam, v. 38, p. 1241-1254, fevereiro de 2011.

[8] DUMAS, M. et al. Fundamentals of Business Process Management. Berlin: Springer-Verlag, 2013.

[9] WESKE, M. Business Process Management: Concepts, Languages, Architectures. 2. ed. Berlin: Springer, 2019.

[10] BURATTIN, A. Process Mining Techniques in Business Environments: Theoretical Aspects, Algorithms, Techniques and Open Challenges in Process Mining. 1. ed. Cham: Springer International Publishing, 2015. v. 207. (Lecture Notes in Business Information Processing, v. 207).

[11] ROSEMANN, M.; RECKER, J.; FLENDER, C. Contextualisation of business processes. International Journal of Business Process Integration and Management, Genebra, v. 3, n. 1, p. 47-60, julho de 2008.

[12] AALST, W. et al. Business process mining: An industrial application. Information Systems, Amsterdam, v. 32, n. 5, p. 713-732, julho de 2007.

[13] BUIJS, A. et al. Understanding People's Ideas on Natural Resource Management: Research on Social Representations of Nature. Society and Natural Resources, Logan, v. 25, n. 11, p. 1167-1181, novembro de 2012.

[14] GRUHN, V.; LAUE, R. Reducing the cognitive complexity of business process models. In: IEEE INTERNATIONAL CONFERENCE ON COGNITIVE INFORMATICS, ICCI, 8., 2009, Hong Kong. Proceedings of the [...]. Washington: Institute of Electrical and Electronics Engineers (IEEE), 2009. p. 339-345.

[15] ABPMP. BPM CBOK: Guia para Gerenciamento de Processos de Negócio. 1. ed. Brasília: Association of Business Process Management Professionals, 2013. 
[16] POLANČIČ, G.; CEGNAR, B. Complexity Metrics for Process Models: A Systematic Literature Review. Computer Standards and Interfaces, Amsterdam, v. 51, p. 104-117, março de 2017.

[17] LINDSAY, A.; DOWNS, D.; LUNN, K. Business processes: Attempts to find a definition. Information and Software Technology, Amsterdam, v. 45, n. 15, p. 1015-1019, dezembro de 2003.

[18] KELLER, G.; NÜTTGENS, M.; SCHEER, A.-W. Semantische Prozeßmodellierung auf der Grundlage "Ereignisgesteuerter Prozeßketten (EPK)". Saarbrücken: Institut für Wirtschaftsinformatik, 1992. v. 89. (Veröffentlichungen des Instituts für Wirtschaftsinformatik, v. 89).

[19] OMG. Business Process Model And Notation 2.0 (BPMN). Milford: Object Management Group (OMG), 2011. Disponível em: 〈https://www.omg.org/spec/BPMN/2.0/ About-BPMN/>.

[20] GUIDOTTI, R. et al. A Survey of Methods for Explaining Black Box Models. ACM Computing Surveys, New York, v. 51, n. 5, p. artigo 93, fevereiro de 2018.

[21] NAKATSU, R. Explanatory power of intelligent systems: a research framework. In: GUPTA, JATINDER N. D. AND FORGIONNE, GUISSEPPI A. AND MORA, MANUEL T. Intelligent Decision-making Support Systems. Londres: Springer-Verlag, 2006. (Decision Engineering), p. 123-143.

[22] SOKOL, K.; FLACH, P. One Explanation Does Not Fit All: The Promise of Interactive Explanations for Machine Learning Transparency. KI - Künstliche Intelligenz, Cham, v. 34, p. 235-250, fevereiro de 2020.

[23] SELFRIDGE, M.; DANIELL, J.; SIMMONS, D. Learning Causal Models by Understanding Real-World Natural Language Explanations. In: CONFERENCE ON ARTIFICIAL INTELLIGENCE APPLICATIONS (CAIA), 2., 1985, Miami Beach. Proceedings of the Second Conference [...]. New York: IEEE Computer Society / North-Holland, 1985. p. 378-383.

[24] RASMUSSEN, J. Human Error and the Problem of Causality in Analysis of Accidents. Philosophical transactions of the Royal Society of London. Series B, Biological sciences, Londres, v. 327, n. 1241, p. 449-60; discussion 460, maio de 1990.

[25] HECKERMAN, D.; SHACHTER, R. A Decision-Based View of Causality. In: UNCERTAINTY IN ARTIFICIAL INTELLIGENCE CONFERENCE, 10., 1994, Seattle. Proceedings of the [...]. Amsterdam: Elsevier, 2013. p. 302-310.

[26] AHN, W. Why are different features central for natural kinds and artifacts?: The role of causal status in determining feature centrality. Cognition, Amsterdam, v. 69, n. 2, p. 13578, janeiro de 1999.

[27] AHN, W.; KALISH, C. The role of mechanism beliefs in causal reasoning. In: KEIL, F. C. AND WILSON, R. A.,
1. Explanation and Cognition. Cambridge: The MIT Press, 2000. p. 199-225.

[28] FELTOVICH, P. J. et al. Keeping it too simple: How the reductive tendency affects cognitive engineering. Intelligent Systems, Washington, v. 19, n. 3, p. 90-94, junho de 2004.

[29] LOMBROZO, T. Simplicity and probability in causal explanation. Cognitive psychology, Amsterdam, v. 55, n. 3, p. 232-57, dezembro de 2007.

[30] LOMBROZO, T. Causal-Explanatory Pluralism: How Intentions, Functions, and Mechanisms Influence Causal Ascriptions. Cognitive psychology, Amsterdam, v. 61, n. 4, p. 303-32, dezembro de 2010.

[31] KLEIN, G. et al. Influencing Preferences for Different Types of Causal Explanation of Complex Events. Human factors, Thousand Oaks, v. 56, n. 8, p. 1380-400, dezembro de 2014.

[32] ROSENBERG, J. On Understanding the Difficulty in Understanding Understanding. In: PARRET, HERMAN AND BOUVERESSE, JACQUES. Meaning and Understanding. Berlim: Walter de Gruyter, 1981. (Grundlagen der Kommunikation und Kognition / Foundations of Communication and Cognition), p. 29-43.

[33] KEIL, F. C. Explanation and Understanding. Annual Review of Psychology, Palo Alto, v. 57, n. 1, p. 227-254, janeiro de 2006.

[34] SMITH, R. Explanation, understanding, and control. Synthese, Berlim, v. 191, p. 4169-4200, novembro de 2014.

[35] HITCHCOCK, C.; WOODWARD, J. Explanatory Generalizations, Part II: Plumbing Explanatory Depth. Noûs, Hoboken, v. 37, n. 2, p. 181-199, maio de 2003.

[36] BYRNE, R. Cognitive Processes in Counterfactual Thinking About What Might have been. Psychology of Learning and Motivation, Amsterdam, v. 37, p. 105-154, dezembro de 1997.

[37] BYRNE, R. Counterfactual Thinking: From Logic to Morality. Current Directions in Psychological Science, Washington, v. 26, n. 4, p. 314-322, agosto de 2017.

[38] HOFFMAN, R. et al. Accelerated Expertise: Training for High Proficiency in a Complex World. 1. ed. New York: Psychology Press, 2013. 1-256 p.

[39] HOFFMAN, R. et al. Accelerated Expertise: Training for High Proficiency in a Complex World. 1. ed. New York: Psychology Press, 2013. 1-256 p.

[40] CHAKRABORTI, T. et al. Plan Explanations as Model Reconciliation: Moving Beyond Explanation as Soliloquy. In: INTERNATIONAL JOINT CONFERENCE ON ARTIFICIAL INTELLIGENCE (IJCAI), 26., 2017, Melbourne. Proceedings of the [...]. San Francisco: International Joint Conferences on Artificial Intelligence, 2017. p. 156-163. 
[41] FOX, M.; LONG, D.; MAGAZZENI, D. Explainable Planning. CoRR, Cornell University, Ithaca, abs/1709.10256, setembro de 2017. Disponível em: 〈http://arxiv.org/abs/1709. $10256\rangle$.

[42] GRAESSER, A.; BAGGETT, W.; WILLIAMS, K. Question-driven Explanatory Reasoning. Applied Cognitive Psychology, Hoboken, v. 10, n. 7, p. 17-31, novembro de 1996.

[43] AHN, W.-k. et al. The role of covariation versus mechanism information in causal attribution. Cognition, Amsterdam, v. 54, n. 3, p. 299-352, abril de 1995.

[44] GOPNIK, A. Explanation as orgasm and the drive for causal knowledge: The function, evolution, and phenomenology of the theory formation system. In: KEIL, F. C. AND WILSON, R. A. Explanation and Cognition. Cambridge: The MIT Press, 2000. p. 299-323.

[45] KEIL, F. Explanation and Understanding. Annual Review of Psychology, Palo Alto, v. 57, p. 227-54, fevereiro de 2006.

[46] KOEHLER, D. Explanation, Imagination, and Confidence in Judgment. Psychological Bulletin, Worcester, v. 110, n. 3, p. 499-519, dezembro de 1991.

[47] LOMBROZO, T.; CAREY, S. Functional explanation and the function of explanation. Cognition, Amsterdam, v. 99, n. 2, p. 167-204, abril de 2006.

[48] MITCHELL, D.; RUSSO, J.; PENNINGTON, N. Back to the future: Temporal perspective in the explanation of events. Journal of Behavioral Decision Making, Hoboken, v. 2, n. 1, p. 25-38, janeiro de 1989.

[49] GIFFIN, C.; WILKENFELD, D.; LOMBROZO, T. The explanatory effect of a label: Explanations with named categories are more satisfying. Cognition, Amsterdam, v. 168, p. 357-369, novembro de 2017.

[50] TWOREK, C.; CIMPIAN, A. Why Do People Tend to Infer "Ought" From "Is"? The Role of Biases in Explanation. Psychological Science, Washington, v. 27, n. 8, p. 1109-1122, abril de 2016.

[51] LINDEN, S. van der et al. Inoculating the Public against Misinformation about Climate Change. Global Challenges, Weinheim, v. 1, n. 2, p. artigo número 1600008 , fevereiro de 2017.

[52] BIRAN, O.; COTTON, C. V. Explanation and Justification in Machine Learning : A Survey Or. In: INTERNATIONAL JOINT CONFERENCE ON ARTIFICIAL INTELLIGENCE (IJCAI), 26., 2017, Melbourne. Proceedings of the [...]. San Francisco: International Joint Conferences on Artificial Intelligence, 2017. p. 8-13.

[53] EINHORN, H.; HOGARTH, R. Judging Probable Cause. Psychological Bulletin, Worcester, v. 99, n. 1, p. 3-19, janeiro de 1986.

[54] HILTON, D. Mental Models and Causal Explanation: Judgements of Probable Cause and Explanatory Relevance.
Thinking and Reasoning, Abingdon, v. 2, n. 4, p. 273-308, novembro de 1996.

[55] MURPHY, G.; MEDIN, D. The role of theories in conceptual coherence. Psychological Review, Worcester, v. 92, n. 3, p. 289-316, janeiro de 1985.

[56] LOMBROZO, T. Explanation and Categorization: How "why?" Informs "What?". Cognition, Amsterdam, v. 110, n. 2, p. 248-53, fevereiro de 2009.

[57] MUELLER, S. et al. Explanation in Human-AI Systems: A Literature Meta-Review, Synopsis of Key Ideas and Publications, and Bibliography for Explainable AI. CoRR, University of Cornell, Ithaca, abs/1902.01876, fevereiro de 2019. Disponível em: 〈http://arxiv.org/abs/1902.01876〉.

[58] CHUNG, K. Asset Characteristics and Corporate Debt Policy: An Empirical Test. Journal of Business Finance and Accounting, Hoboken, v. 20, n. 1, p. 83-98, dezembro de 2006.

[59] HAMSCHER, W. AI in Business-Process Reengineering. AI Magazine, Washington, v. 15, n. 4, p. 71-72, dezembro de 1994.

[60] VERENICH, I. Explainable predictive monitoring of temporal measures of business processes. Tese (Doutorado em Filosofia) - Queensland University of Technology, 2018.

[61] SCHNEIDER, T. et al. Earth System Modeling 2.0: A Blueprint for Models That Learn From Observations and Targeted High-Resolution Simulations. Geophysical Research Letters, Hoboken, v. 44, n. 24, p. 12,396-12,417, agosto de 2017.

[62] GUIDOTTI, R. et al. A Survey of Methods for Explaining Black Box Models. ACM Computing Surveys, New York, v. 51, n. 5, p. artigo 93, fevereiro de 2018.

[63] HARL, M. et al. Explainable predictive business process monitoring using gated graph neural networks. In: HEAVIN, Ciara et al. Journal of Decision Systems - Latest Articles. Londres, 2020.

[64] FOX, M. The TOVE Project Towards a Common-Sense Model of the Enterprise. In: IEA/AIE: INTERNATIONAL CONFERENCE ON INDUSTRIAL, ENGINEERING AND OTHER APPLICATIONS OF APPLIED INTELLIGENT SYSTEMS, 5., 1992, Paderborn. Proceedings of the [...]. Berlim: Springer, 1992. (Lecture Notes in Computer Science, v. 604), p. 25-34.

[65] ANGELE, J. et al. Developing Knowledge-Based Systems with MIKE. Automated Software Engineering, Berlim, v. 5, p. 389-418, outubro de 1998.

[66] GUNNING, D. et al. XAI-Explainable artificial intelligence. Science Robotics, Washington, v. 4, n. 37, dezembro de 2019.

[67] ARRIETA, A. B. et al. Explainable Artificial Intelligence (XAI): Concepts, Taxonomies, Opportunities and Challenges toward Responsible AI. Information Fusion, Amsterdam, v. 58, p. 82-115, junho de 2020. 
[68] HOFFMAN, R. et al. Metrics for Explainable AI: Challenges and Prospects. CoRR, Ithaca, abs/1812.04608, dezembro de 2018.

[69] CARDOSO, J. Business Process Control-Flow Complex- ity: Metric, Evaluation, and Validation. International Journal of Web Services Research, Hershey, v. 5, n. 2, p. 49-76, abril de 2008. 